\title{
Insurance Economics and Theory of Option Pricing: A Proposal
}

\author{
Chao Chiung Ting ${ }^{1}$ \\ ${ }^{1}$ Michigan State University Graduated, United States \\ Correspondence: Chao Chiung Ting, Michigan State University Graduated, 6333 98th Place 1E, Rego Park NY \\ 11374, United States. E-mail: tingtch7ti@aol.com
}

Received: August 8, 2014

Accepted: August 22, 2014

Online Published: November 25, 2014

doi:10.5539/ijef.v6n12p178

URL: http://dx.doi.org/10.5539/ijef.v6n12p178

\begin{abstract}
Probability and maximum expected utility under risk aversion are corner stone of the contemporary insurance economics. Since economists use arbitrage assumption and riskless portfolio to construct the modern theory of option pricing, probability plays no role to determine option price under uncertainty. It is wrong that the contemporary insurance economics and the modern theory of option pricing are irrelevant and opposite because all prices of substitute products (e.g., portfolio insurance and option) should be explained by the same independent variables. Since option pricing is supposed to be similar to insurance pricing, the purpose of this paper is to propose a single price theory that explains both the premium of portfolio insurance and option price.
\end{abstract}

Keywords: insurance economics, option pricing

\section{Overview and Organization}

\subsection{Option and Portfolio Insurance Are Substitute Products}

Economists have recognized that option and insurance are analogous for decades. There are many examples that authors introduced this analogy to readers briefly but authors did not intend to investigate the relation between insurance premium and option price in their publications. Crack (2009, p. 1) wrote "options may be viewed as insurance contract. Payment for an option is, correspondingly, called the option "premium" and a seller who did not already own the option is referred to as an option "writer"." Carlson (2006, p. 4) stated "Buying portfolio insurance was similar to buying a put option in that allowed investors to preserve upside gains but limit downside risk." Mayers and Smith (1983, p. 304) addressed in abstract "We analyze the individual's demand for insurance as a special case of general portfolio hedging activity."

In this paper, option means the right to buy or sell a single share of stock by a certain date for a certain price. Consider a case that an economic agent purchases one share of stock by $\$ 100$ and one option put with strike price equal to $\$ 100$. If stock price drops, say $\$ 80$, the economic agent can exercise the option put he already bought to avoid loss. That is, he buys one share of stock from stock market by $\$ 80$ and then he sells one share of stock to option writer by $\$ 100$. It illuminates that option hedgers pay money to option writers for shifting their own risk originating from their investment on stock to option writers as if the inured pay insurance premium to insurers for shifting their own risk to insurers. Thus, option and portfolio insurance are substitute products because they have the same property: risk shifting.

If option is more expensive than portfolio insurance, economic agents should buy portfolio insurance instead of option. Of course, economic agents substitute option for portfolio insurance when option is cheaper than portfolio insurance. The premium of portfolio insurance and option price are interdependent.

\subsection{Irrelevancy Between Insurance Economics and Theory of Option Pricing}

The benchmark of the contemporary insurance economics is probability and maximum expected utility under risk aversion (e.g., Borch, 1962; Arrow, 1963; Mossin, 1968; Raviv, 1979). In the modern theory of option pricing, economists applied arbitrage assumption and riskless portfolio to determine option price under uncertainty (e.g., Black \& Scholes, 1973). It is an essential characteristic of the modern theory of option pricing that probability disappears. Thus, the contemporary insurance economics and the modern theory of option pricing are absolutely irrelevant and opposite in spite of the fact that portfolio insurance and option are substitute products.

If economists understand substitute products completely, economists should not accept this irrelevancy and leave 
the interwoven theoretical relation between the premium of portfolio insurance and option price to be blank. Assume that there are $N$ substitute products and there is an independent variable $x_{k}$ which affects the price of $N_{t h}$ substitute product only, $P_{N}=P_{n}\left(P_{1} \ldots P_{N-1}, x_{1} \ldots x_{k}\right)$ and $\frac{\partial P_{N}}{\partial x_{k}} \neq 0$. Since $x_{k}$ does not affect prices of all substitute products except the $N_{t h}$ substitute product, $\frac{\partial P_{i}}{\partial x_{k}}=0$ and $i \neq N$. But the change in the price of the $N_{t h}$ substitute product $\left(\Delta P_{N}\right)$ transmits the impact arising from $x_{k}$ on the price of $N_{t h}$ substitute product $\left(\frac{\partial P_{N}}{\partial x_{K}}\right)$ to prices of other substitute products (i.e., $\frac{\partial P_{i}}{\partial P_{N}} \frac{\partial P_{N}}{\partial x_{k}} \neq 0$ and $i \neq N$ ) due to the reason all prices of substitute products are interdependent. Since $\frac{\partial P_{i}}{\partial x_{k}}=\frac{\partial P_{i}}{\partial P_{N}} \frac{\partial P_{N}}{\partial x_{k}}$ and $\frac{\partial P_{i}}{\partial P_{N}} \frac{\partial P_{N}}{\partial x_{k}} \neq 0$, we have $\frac{\partial P_{i}}{\partial x_{K}} \neq 0$. This conclusion is against the assumption that $\frac{\partial P_{i}}{\partial x_{K}}=0$. It means that $x_{K}$ is impossible to exist. Thus, all prices of substitute products should be derived from the same independent variables and $P_{i}\left(P_{1} \ldots P_{I-1}, P_{I+1} \ldots P_{N}, x_{1} \ldots x_{k}\right)$ can be replaced by $P_{i}\left(x_{1} \ldots x_{\mathrm{K}}\right)$.

I derive two inferences from the conclusion in the last paragraph. First, we can unify price theories of substitute products by the same independent variables if each substitute product has its own price theory. Second, the irrelevancy and the opposition between the contemporary insurance economics and the modern theory of option pricing imply incorrectness because independent variables from which economists deduced the premium of portfolio insurance have been different from independent variables from which economists derived option price since the beginning. It is inevitable that economists have to cure this incorrectness; otherwise, economics is not scientific. Thus, the objective of this paper is to propose an unified price theory that explains both the premium of portfolio insurance and option price by the same independent variables like Ting (2011) unified different business cycle theories to one and Ting (2010) integrated growth theory in macroeconomics and the growth theory of the firm.

In addition, Cummins (1990) admitted that financial economics used asset pricing models (e.g., Black \& Scholes, 1973) under market equilibrium and arbitrage assumption to study insurance premium. The contemporary insurance economics and the theory of insurance pricing in financial economics are irrelevant and opposite, either. Since insurance pricing in financial economics is similar to the modern theory of option pricing, I do not discuss the insurance pricing in financial economics in this paper.

\subsection{Organization of This Paper}

In section II, I use duality to demonstrate that maximum expected utility hypothesis and maximum efficiency hypothesis are consistent. I substitute maximum efficiency hypothesis for maximum expected utility hypothesis and risk aversion assumption to analyze demand for insurance financially. Insurance premium is cost and input. Reduction in the variation of wealth is reward and output. Since insurance corporations do not sell insurance contract by each unit of reduction in the variation of wealth (i.e., there is no price for one unit of reduction in variation of wealth), we have to use the ratio of total output to total input to measure efficiency. Further, the total cost is the monetary value of total input and, therefore, we can use the ratio of total output to total cost to measure efficiency. Thus, economic agents should select the insurance coverage that maximizes the ratio of reduction in the variation of wealth to insurance premium. If we reverse this ratio (i.e., total cost is divided by total output), the reversed ratio means minimization of the average cost of reduction in the variation of wealth. Moreover, maximum efficiency hypothesis allows economic agents to pursue profit as well as avoid risk by hedge or insurance simultaneously. Economists usually apply risk neutral assumption (i.e., you do not insure or hedge if you pursue profit) to study behavior of insurance corporations about the optimal insurance contract (e.g., Raviv, 1979) due to the reason that insurance corporations pursue profit. It implies that all firms are risk neutral because all firms pursue profit. Thus, the risk neutral assumption is abandoned when I consider demand for insurance and demand for hedge by firms. Note that economists have never investigated the topic of the optimal strike price of option hedging activities but maximum efficiency hypothesis can determine the optimal strike price.

I criticize the approach based on arbitrage assumption and riskless portfolio in the modern theory of option pricing in section III. Consider a riskless portfolio consisting of a long position of stock index, say Dow Jones, and a long position of Dow Jones option put. Since the return rate on capital of every riskless portfolio is required to be equal to interest rate due to arbitrage assumption and investors buy Dow Jones stock index by the above riskless portfolio every day, Dow Jones is required to rise continuously by arbitrage assumption. Otherwise, all investors who apply the above portfolio to buy Dow Jones stock index are impossible to have the same return rate on capital as interest rate. This conclusion deduced from arbitrage assumption is against the fact 
that stock indexes are random walk and stock indexes may fall continuously. If we deduce a false conclusion from a particular combination of premises (e.g., arbitrage assumption and riskless portfolio), this combination is false. Thus, we have to reject the approach based on riskless portfolio and arbitrage assumption.

Second, I will show that return rates on capital of different riskless portfolios are definitely not identical in section III. It implies that the return rate on a stock-option riskless portfolio may be different from interest rate. Thus, we cannot use arbitrage assumption to require the return rate on a stock-option riskless portfolio to be equal to interest rate. It is the third objection that riskless portfolio and arbitrage assumption concern demand for option only. Since price is determined by supply and demand and the modern theory of option pricing ignores supply of option completely, option price is actually indeterminate in the modern theory of option pricing.

I have to prove that the modern theory of option pricing is wrong because I argue that both the premium of portfolio insurance and option price should be explained by the same independent variables and I prove that the combination of riskless portfolio and arbitrage assumption is false. I discuss binominal model developed by Cox, Ross and Rubinstein (1979) in section IV. In binominal model, option price depends on stock price, strike price, outcome stock price and interest rate. Binominal model implies that we derive the same option price from all stock-option riskless portfolios while stock price, strike price, outcome stock price and interest rate are given. But Ting (2013) demonstrated the possibility that we can deduce different option prices from particular stock-option riskless portfolios under binominal model while stock price, strike price, outcome stock price and interest rate are given. It means that binominal model is self-contradictory. I will generalize Ting's argument in order to show that we definitely deduce different option prices from stock-option riskless portfolios under binominal model while stock price, strike price, outcome stock price and interest rate are given. In section V, I disclose that the logic structure of Black and Scholes is self-contradictory so as to disprove the argument of Black and Scholes.

Since option writers take over risk from option buyers, the way that option writers charge option price is supposed to be the same as the way that insurance companies quote insurance premium based on expected loss caused by accidents. Of course, the option price that option hedgers are willing to pay is similar to the expected loss estimated by the insured. Like option hedgers assess expected loss by strike price and expected stock price, the expected profit of a particular option speculator depends on the difference between strike price and the stock price that the option speculator expects. Thus, expected payoff is the independent variable that explains both option price and insurance premium in the rest of this paper.

The rest of this paper is organized as below. Section VI discusses demand for insurance in which I demonstrate that partial coverage insurance is the optimal strategy to maximize efficiency. I investigate supply of insurance in section VII. Section VIII explores option price. Although Lo and Wang (1995, p. 91) indicated "the option's price is simply the present discounted value of its expected payoff at maturity," economists still insist that option price should depend on both spot stock price and strike price, e.g., Black and Scholes (1973). I will argue that option price depends on the probability distribution of expected stock price and strike price. Finally, I remark reviews and propose economic policies in section IX.

\section{Deficiency of Maximum Utility and Risk Aversion}

\subsection{Maximum Utility Cannot Determine Demand for Insurance}

In microeconomics, economists present maximum utility hypothesis by a simple equation.

$$
\operatorname{Max} U(Y, Z)+\lambda\left(W-P_{Y} Y-P_{Z} Z\right)
$$

In equation (1), endowed wealth $(W)$ and prices $\left(P_{Y}\right.$ and $\left.P_{Z}\right)$ are given exogenously. Suppose that an economic agent plans to consume bread (product $Y$ ) and invest on option (product $Z$ ). Since option does not bring utility to the economic agent, maximum utility cannot analyze financial resources allocation. There are a lot of situations that households have to make a financial decision. To purchase a house or to rent a house is a financial decision rather than a decision about consumption of housing. To keep the house you own or sell it is a financial decision, too. As the demand for input factors is the demand derived from the demand for final goods in microeconomics, the demand for house insurance is derived from house purchasing or house ownership. If maximum utility cannot determine house purchasing or house ownership, maximum utility cannot analyze demand for house insurance completely and soundly.

In insurance economics, equation (1) is transformed into

$$
\operatorname{Max} \int_{0}^{\infty} U(W-P-x+I) f(x) d x
$$

In equation (2), endowed wealth and loss caused by accidents $(x)$ are given exogenously by economists. $f(x)$ is 
the probability distribution of loss. Economists tried to determine insurance premium $(P)$ and indemnity $(I)$ endogenously by risk aversion, e.g., Raviv (1979) and Mossin (1968). Since budget constraint does not appear in equation (2), the combination of risk aversion and equation (2) cannot describe how households or firms allocate their own resources into different purposes optimally, either. Thus, the optimal insurance coverage derived from equation (2) is unsound from the view point of general equilibrium.

\subsection{Risk Aversion Creates Dilemma}

Economists usually use a fair-coin-toss game to display the idea of risk aversion. Assume that the payoff of a fair-coin-toss game is either $\$ 2$ or zero while the bet is $\$ 1$. Since risk aversion assumes that economic agents who are risk averse prefer $\$ 1$ guaranteed revenue to $\$ 1$ expected revenue, economic agents who are risk averse do not play the fair-coin-toss game. Arrow (1965) and Praat (1964) introduced risk premium into the measure of risk aversion. They assumed that economic agents feel indifferent between the $\$ 1$ guaranteed revenue and risk premium plus the $\$ 1$ expected revenue (i.e., cash equivalent). Economic agents play game if the expected payoff of a game is greater than cash equivalent.

Risk aversion creates a dilemma that economic agents who are risk averse do not play game instead of demand for insurance. For example, an individual who is risk averse is supposed to hold cash rather than buy a house because a house may be destroyed by flood, fire and hurricane. If economic agents who are risk averse do not purchase house, they do not demand for house insurance. Thus, the relation between risk aversion and demand for insurance is ambiguous. The correct methodology based on risk aversion assumption is that economic agents buy property due to the reason that the benefit yielding from property is greater than cash equivalent financially and then risk aversion drives economic agents to buy property insurance. Thus, we have to introduce resources allocation into the theory of demand for insurance because we need resource allocation to determine demand for final goods and demand for insurance simultaneously. Since risk aversion alone cannot determine resources allocation financially, risk aversion cannot analyze demand for insurance under general equilibrium.

To run business is similar to game playing because you may make profit or you may lose money. The dilemma mentioned above is still valid. For instance, an entrepreneur who is risk averse would not produce gasoline rather than buy insurance for his gasoline refinery because gasoline price fluctuates. To overcome this dilemma, economists introduced risk neutral assumption into economics in order to explain why economic agents pursue profit under risk. Risk neutral assumption suggests that the firm is supposed not to hedge or insure while the objective of the firm is to pursue profit. But we have observed that the firm not only pursue profit by risky business but also avoid risk by hedge and insurance. For example, oil producer hedges oil price (e.g., Jin \& Jorion, 2006) and corporations buy currency derivatives (e.g., Geczy, Minton, \& Schrand, 1997) because entrepreneurs are risk averse and then entrepreneurs hedge in order to reduce the variation of revenue despite entrepreneurs take risk to pursue profit. In addition, risk aversion cannot explain why speculators (e.g., fund managers) invest derivatives as well as hedge and why entrepreneurs not only establish insurance corporations but also reinsure because speculators and insurers are risk love while hedge and reinsurance are risk aversion activities. Note that entrepreneurs will not establish insurance corporations if entrepreneurs are risk averse due to the reason that economic agents who are risk averse do not play game and insurance corporations play game.

Since risk aversion neither shows us how the firm allocates resources into insurance and productive activities nor describes behavior of the firm properly, some economists already acknowledged that risk aversion is inappropriate to analyze demand for insurance. Mayers and Smith (1982, p. 281) complaint "Although risk aversion is unquestionably at the heart of the demand for insurance of individuals, it provides an unsatisfactory basis for analyzing the demand for insurance by corporations." Complementally, Davidson, Cross and Thornton (1992) found that risk aversion did not explain the demand for insurance by corporations empirically.

\subsection{Demand for Insurance Is a Financial Decision}

Insurance premium and indemnity affect the variation of wealth, which is measured by the variance of expected loss. Insurance premium is equal to actuarial value (i.e., the expected loss occurring to the insured and the expected indemnity expenditure of insurers) plus loading because insurers have to make profit. Since insurance premium paid by the insured is greater than indemnity received by the insured in the long run, reduction in the variation of wealth is the true financial reward accruing form insurance, not indemnity received by the insured. In other words, insurance premium is input (i.e., cost) and reduction in the variation of wealth is output (i.e., reward). Thus, the maximum efficiency of insurance coverage is either the highest ratio of reduction in the variation of wealth to insurance premium or the greatest ratio of the variation of wealth covered by insurance to insurance premium. If we reverse these two ratios, we get minimum average cost. Maximum efficiency and minimum average cost are dual. 
Since reduction in the variation of wealth makes economic agents feel safer, insurance brings utility to the insured. Maximum expected utility hypothesis is appropriate. Maximum efficiency hypothesis is correct because insurance is a financial instrument to reduce the variation of wealth. Are these two hypotheses consistent? There are two dualities in microeconomics. One is maximum utility and minimum cost. The other is maximum profit (i.e., maximum efficiency) and minimum cost. Minimum cost allocates resources efficiently like budget constraint functions in equation (1). Unlike maximum utility, minimum cost is compatible with consumption goods, physical assets, financial assets and reduction in the variation of wealth. Minimum cost implies that economic agents can release resources to improve their happiness if economic agents do not maximize the efficiency of their assets. By duality, an economic agent who fulfills minimum cost will practice both maximum efficiency and maximum utility simultaneously. That is, I restate the goal of economic agents to be: minimum cost subject to given utility and given reduction in the variation of wealth or minimum cost subject to given profit and given reduction in the variation of wealth. In other words, economic agents use maximum efficiency to determine how much resources will be allocated into risk shifting activities under minimum cost. Since maximum efficiency hypothesis and maximum utility hypothesis are consistent, I replace maximum expected utility under risk aversion by maximum efficiency to financially analyze not only the demand for insurance of households but also the demand for hedge of the firm and speculators. Thus, the deficiency of maximum utility and risk aversion is overcome.

\section{Shortcomings of Arbitrage Assumption and Riskless Portfolio}

\subsection{Arbitrage Profit Exists in the Real World}

Arbitrage assumption states that financial assets have the same return rate on capital if financial assets are equivalent. Assume that there are two financial markets, say market A and market B. Capital will transfer from market $\mathrm{A}$ to market $\mathrm{B}$ if the yield of market $\mathrm{A}$ is higher than the yield of market $\mathrm{B}$ and these two markets have the same risk level. Economists name the difference in yielding as arbitrage profit. If market B is riskier than market A and these two markets have the same return rate on capital, money will shift from market B to market A. The difference in risk between two markets is arbitrage risk. Money transfer from one market to another market if and only if arbitrage profit and arbitrage risk exist. Since we observe that monetary capital transfer daily, we assure that arbitrage profit and arbitrage risk prevail in the economy we are living. Thus, arbitrage assumption is a false premise because arbitrage assumption is against observations. The modern theory of option pricing is wrong because we cannot use false premises to construct a true theory. For example, we cannot use the assumption that sun rotates around earth from east to west to be premise for explaining perfectly why sun rises at east and sun sets at west.

Moreover, monetary policy determines interest rate. The combination of arbitrage assumption and riskless portfolio suggests that Federal Reserve determines the return rate on capital of every riskless portfolio and the return rate on stock indexes investment. Dow Jones was 13,104 at 12/31/2012 and ended 15,576 at 12/31/2013. The average interest rate of one year US treasury security was 0.11 percent in 2013 . The matter of fact is that the return rate on Dow Jones was greater than the interest rate manipulated by Federal Reserve in 2013. It implies that arbitrage profit exists in stock market and the return rate on the riskless portfolio consisting of stock and option is determined by the stock price in the future instead of interest rate. Thus, arbitrage assumption is a false premise to explain option prices we have observed and, therefore, we have to reject arbitrage assumption.

Arbitrage profit and arbitrage risk vanish if and only if all markets simultaneously reach equilibrium under uncertainty. Thus, the option price determined by the modern theory of option pricing would be equilibrium option price if the modern theory of option pricing were to be correct. Since arbitrage profit and arbitrage risk exist in the real world, market option price is different from equilibrium option price. But the objective of the modern theory of option pricing is to explain market option prices. When we apply the equilibrium option price derived from the modern theory of option pricing to predict market option price statistically, errors and biases are inherent no matter whatever effort is made to revise Black-Scholes formula by economists. Empirical evidence supports this prediction. Singh (2013) found that practitioner Black-Scholes model, Gram-Charliers model, Hull-white uncorrelated stochastic volatility model and Hestom model are all not able to eliminate bias completely.

\subsection{Riskless Portfolios Are Not Equivalent to Each Other}

Consider two riskless portfolios. One consists of a long position of stock and a long position of option put. The other is composed of a short position of stock and a long position of option call. If stock price rises, the former portfolio makes profit and the latter portfolio is break even. If stock price falls, the former portfolio does not lose money and the latter portfolio brings reward to you. But it is impossible that these two riskless portfolios are 
profitable at the same time. In this case, one return rate on riskless portfolio in this example at least is definitely different from interest rate. We can generalize this example. Whenever economic agents design a riskless portfolio, we can get a corresponding riskless portfolio by reversing the short-long relation among components. For example, a riskless portfolio consisting of a long position of stock and a short position of option call corresponds to the reversed riskless portfolio composed of a short position of stock and a long position of option call. Thus, riskless portfolio and arbitrage assumption are inconsistent definitely because return rates on capital of different riskless portfolios are different and arbitrage assumption requires that return rates on capital of all riskless portfolios should be the same as interest rate. Since we can deduce contradictory conclusions from inconsistent premises (e.g., binominal model in section IV), economists must reject the approach based on arbitrage assumption and riskless portfolio.

Economists may argue that expected return rates on capital of different riskless portfolios should be equivalent instead of actual return rates on capital. Since the expected reward earning from upward stock price is equal to the expected profit yielding from downward stock price, this argument requires that the probability distribution of stock price should be symmetric. Since the actual probability distribution of stock price is not symmetric, this requirement is a false premise. False premise should be rejected by us.

\subsection{Supply of Option and Risk Shifting}

Unlike insurance premium, option price does not relate to the expected loss that option writers take over from option buyers in the modern theory of option pricing. In other words, the modern theory of option pricing ignores supply of option intentionally. Why? The first reason I guess is the myth that the loss arising from option put selling is offset by the profit originating from option call selling and vice versa. The profit originating from option selling is predetermined by option price. If stock price rises more than the price of option put, option writers' deficit arising from option call selling is greater than the profit generating from option put selling. Similarly, the profit arising from option call selling cannot offset the deficit originating from option put selling if stock price falls more than the price of option call.

Besides, the number of outstanding option put may be different from the number of outstanding option call. As the case of run on the bank that all depositors have unanimous expectation about bank default and then all depositors withdraw deposit simultaneously, option writers may face huge loss due to the reason that economic agents have unanimous expectation about the future. For example, economic agents buy option put when stock market is bull and, therefore, option writers cannot shift risk taking over from option put buyers to option call buyers. When bull stock market converts into bear stock market suddenly and turbulently like 1987, option writers suffer huge loss. The recent case is AIG credit default SWAP in 2008 because all economic agents had expected that subprime loan would default. Thus, option price must depend on expected loss like insurance premium.

Second, economists may argue that option writers are riskless because option writers sell option call and then option writers buy stock in order to shift risk arising from option call selling to economic agents who plan to build up their own short positions of stock. If stock price declines more than the price of option call charged by option writers, the loss arising from the stock purchase of option writers is greater than the revenue originating from option call selling. In this case, option writers still lose money (i.e., option writers are not fully riskless). Besides, the capital that option writers need to buy stock for exposing the risk of option call selling is greater than the revenue originating from option call selling due to the reason that stock price is much higher than the price of option call. Thus, this strategy seems to be impractical because the extra capital needed by option writers for exposing risk may be too large to practice risk shifting.

Moreover, economic agents who short stocks to option writers may construct the riskless portfolio consisting of a short position of stock and a long position of option call next in order to reduce their own risk. In this case, option writers take over new risk. It creates an endless loop of risk shifting, which makes economic agents including option writers feel safe. But risk cannot be wiped off if we take option market and stock market as a whole. Since the endless loop is similar to the music chair mentioned in the chapter 12 of General Theory, someone must suffer from loss when game is over (i.e., endless loop is terminated by exogenous forces) .

In short, the expected loss that option writers take over from option buyers is an indispensable factor when option writers set option price for their supply of option.

\section{Binominal Model}

I use the example of Hull (2003, pp. 200-201) to illustrate that we definitely deduce contradictory option prices from binominal model. 
Case I. Consider a portfolio consisting of a long position of $\Delta$ share of stock and a short position in one three months European option call. Spot stock price is $\$ 20$. Strike price is $\$ 21$. Outcome stock prices are either $\$ 22$ or $\$ 18$. Interest rate is 12 percent annually.

If outcome stock price is $\$ 22$, the short position of one option call loses $\$ 1$. Thus, the value of this portfolio is $22 \Delta$ - 1. If outcome stock price is $\$ 18,18 \Delta$ is the value of this portfolio. By delta hedge, the value of this portfolio is a constant. Therefore, $\Delta=0.25$ because $22 \Delta-1=18 \Delta$. Since the value of this portfolio is $\$ 4.5$ $(18 \times 0.25$ or $22 \times 0.25-1)$, the price of three months European call is $\$ 0.633\left(5-4.5 e^{-0.12 \times \frac{3}{12}}\right)$ for two reasons. First, net investment must be $\$ 4.327$, which will grow to be $\$ 4.5$ three months later. Second, the revenue originating from short position of option call must be $\$ 0.633$ because your net investment is $\$ 4.327$ and you spend $\$ 5$ to buy 0.25 share of stock.

Whenever economic agents design a particular riskless portfolio based on stock and option, we can reverse the relation between stock and option to get a new riskless portfolio. I reverse the relation between stock and option in case I to get case II.

Case II. Consider a portfolio composed of a short position of $\Delta$ share of stock and a long position in one three months European option call. Other things are the same as Case I.

If outcome stock price is $\$ 22$, the value of this portfolio is equal to $20 \Delta$ (cash accruing from short position of stock) $+\$ 1$ (profit earning from European option call) $-22 \Delta$ (repay the stock borrowing for short position). If outcome stock price is $\$ 18$, the value of this portfolio is $2 \Delta$. By $1-2 \Delta=2 \Delta, \Delta$ is equal to 0.25 and the value of this portfolio is $\$ 0.5$. Thus, your net investment is $0.485\left(0.5 \times e^{-0.12 \times \frac{3}{12}}\right)$. Since there is $\$ 5$ cash revenue accruing from short position of stock and the net investment in this case is $\$ 0.485$, the price of three months European call is $\$ 5.485$.

The profitability of a long position of option depends on the stock price in the future (i.e., outcome stock price in binominal model). The profitability of a short position of option is predetermined by the selling price of option. They are different. Once we manipulate outcome stock prices, we can derive contradictory option price definitely. Second, the amount of cash yielding from a short position of option is different from the amount of cash originating from a short position of stock because stock price is usually higher than option price. These two reasons explain why binominal model is self-contradictory definitely.

\section{Black-Scholes Formula}

Black and Scholes (1973, p. 638) wrote "the current value of the option will thus be approximately equal to the price of the stock minus the price of a pure discount bond that matures on the same date as the option, with a face value equal to the striking price of the option." Further, Black and Scholes (1973, p. 641) addressed "writing $w(x, t)$ for the value of the option as a function of stock price $x$ and time $t$, the number of options that must be sold short against one share of stock long is $1 / w_{1}(x, t)$ " and "if the stock price changes by an amount $\Delta \mathrm{x}$, the option price will change by an amount $\mathrm{w}_{1}(x, t) \Delta \mathrm{x} . "$

Let $S$ and $s$ be spot stock price and strike price respectively. Following page 638 of Black and Scholes, the price of an American option call is $\operatorname{Max}(0, S-s)$ and the price of an American option put is $\operatorname{Max}(0, S-s)$ because you are allowed to exercise American option call at any time before expiration date and, therefore, discount factor does not work. For American option, the change in stock price is equal to the change in the price of American option, $\Delta x=\Delta w$. By $\Delta w=w_{1}(x, t) \Delta x$ and $\Delta w=\Delta x$, we get $\mathrm{w}_{1}(x, t)=1$. It makes the equation (3) of Black and Scholes (1973) $\left(\Delta x-\Delta w / w_{1}\right)$ become zero. The price of an European option call is $\operatorname{Max}\left(0, S-s e^{-r t}\right)$ and the price of an European option put is $\operatorname{Max}\left(0, s^{-r t}-S\right)$. The change in stock price is still equal to the change in the price of European option. The equation (3) of Black and Scholes becomes zero once more.

I substitute equation (4) of Black and Scholes $\left(\Delta w=w_{1} \Delta x+\frac{1}{2} w_{11} v^{2} x^{2} \Delta t+w_{2} \Delta t\right)$ into equation (3) of Black and Scholes as Black and Scholes did. I get $\frac{1}{2} w_{11} v^{2} x^{2}+w_{2}=0$. This result is contradictory to the equation (6) of Black and Scholes, $-\left(\frac{1}{2} v^{2} x^{2} w_{11}+w_{2}\right) \frac{\Delta t}{w_{1}}=\left(x-\frac{w}{w_{1}}\right) r \Delta t$. I conclude that the logic structure of Black and Scholes is self-contradictory. There is another fatal mistake made by Black and Scholes. I argued that in III.2 that we cannot require the return rate on riskless portfolio to be equal to interest rate. Thus, the return of delta hedge may be different from $\left(x-\frac{w}{w_{1}}\right) r \Delta t$.

\section{Demand for Insurance}

Let $x$ and $f(x)$ be loss caused by accidents and the probability distribution of loss respectively. 


$$
\begin{aligned}
& \mu=\int_{0}^{\infty} x f(x) d x \\
& \sigma^{2}=\int_{0}^{\infty}(\mu-x)^{2} f(x) d x
\end{aligned}
$$

Equation (3) is the mean value of expected loss (i.e., actuarial value of full coverage insurance). Equation (4) is the variance of expected loss. Gollier (2003) stated that loading factor is around 30 percent for insurance pricing. Insurance companies will charge $(1+\eta) \mu$ for full coverage insurance, where $\eta$ is loading factor. Thus, the expected wealth of the economic agent who purchases full coverage insurance is $W-(1+\eta) \mu$. Economic agents pay $\eta \mu$ to protect their own wealth because the expected wealth of the economic agent who does not buy insurance is $\int_{0}^{\infty}(W-x) f(x) d x=W-\mu$. Thus, we can apply input-output analysis to study insurance.

Let $I$ be the minimum indemnity of a particular partial coverage insurance contract.

$$
\begin{gathered}
P=\int_{I}^{\infty} x f(x) d x \\
\mu-P=\int_{0}^{I} x f(x) d x \\
\sigma_{I}^{2}=\int_{0}^{I}((\mu-P)-x)^{2} f(x) d x
\end{gathered}
$$

$P$ is the actuarial value of a particular partial coverage insurance contract. $\mu-P$ is the mean value of loss uncovered by the particular partial coverage insurance. $\sigma_{I}^{2}$ is the variance of uncovered loss. $\sigma^{2}-\sigma_{I}^{2}$ is the variation reduced by the particular partial coverage insurance. The solution for optimal coverage is as below.

$$
\begin{gathered}
\operatorname{Max} \frac{\sigma^{2}-\sigma_{I}^{2}}{(I+\eta) P} \\
\frac{\partial \sigma^{2}-\sigma_{I}^{2}}{\partial I}(1+\eta) P-\left(\sigma^{2}-\sigma_{I}^{2}\right)(I+\eta) \frac{\partial P}{\partial I}=0 \\
\frac{\partial \sigma^{2}}{\partial I}=0 \\
\frac{\partial P}{\partial I}=\frac{\partial \int_{I}^{\infty} x f(x) d x}{\partial I}=-I f(I) \\
I=\frac{\frac{\partial \sigma_{I}^{2}}{\partial I} P}{\left(\sigma^{2}-\sigma_{I}^{2}\right) f(I)}
\end{gathered}
$$

We know $\int_{I}^{\infty} x f(x) d x=F(\infty)-F(I)$. Since $f(\infty)=0$ (i.e., the probability that loss is infinitive is equal to zero), $F(\infty)$ is equal to zero. By $\frac{\partial \int x f(x) d x}{\partial x}=x f(x), \frac{\partial F(I)}{\partial I}=I f(I)$. The higher deduction you choose, the less insurance premium you pay. Similarly, equation (11) means that the actuarial value of this partial coverage insurance decreases $I f(I)$ if the minimum indemnity increases from $I-\Delta I$ to $I$. Since the variance of expected loss $\left(\sigma^{2}\right)$ defined by equation (4) is independent of the minimum indemnity $(I)$, we have equation (10). When the minimum indemnity approaches zero, equation (5) approximates the actuarial value of full coverage insurance and equation (7) converges to zero. Thus, equation (8) can estimate the efficiency of full coverage insurance. Equation (12) demonstrates that partial coverage insurance is more efficient than full coverage insurance because the optimal minimum indemnity is not equal to zero in equation (12). Once the minimum indemnity is optimal, insurance coverage that corresponds to the optimal minimum indemnity is optimal. Since insurance premium depends on insurance coverage, the optimal minimum indemnity determines demand for insurance (i.e., how much resources will be allocated into insurance by economic agents).

Since portfolio insurance and option are substitute products, both the optimal coverage of portfolio insurance and the optimal coverage of option hedge (i.e., the optimal strike price) are supposed to be derived from the same methodology. That is the reason why I have to discuss demand for insurance although the primary objective of this paper is option pricing. I would like to suggest readers to study the optimal coverage of insurance in this section and the optimal strike price in section 7 comparatively.

\section{Supply of Insurance}

Since insurance companies collect insurance premium in the beginning of a period but pay indemnity gradually during the period, insurance companies can earn interest revenue from cash management. Bamoul (1952) showed that transaction demand for money is a function of interest rate and transaction cost for selling and purchasing financial assets. Bessembinder and Maxwell (2008) reported that the round-trip transaction cost of US treasury security is 0.08 percent and US treasury security accounts for 59 percent of total bond trading 
volume in 2006. It alludes that US treasury security is the tool of financial institutions to manage idle cash for its high trading volume and low transaction cost. The paper of Bessembinder and Maxwell allows me to ignore transaction cost in order to avoid the complexity like Bamoul's paper. I assume that insurance companies divide a period into $N$ sub-periods. Let $M$ be total insurance premium collected by insurance companies. In each sub-period, insurance companies need $M / N$ for indemnity expenditure. Interest rate is $r / N$. Under this ideal condition, insurance companies earn.

$$
\sum_{i=1}^{i=N} \frac{(N-i) M}{N} \frac{r}{N} \cong \frac{M r}{2}
$$

Since insurance companies pursue profit, we have

$$
\begin{gathered}
\operatorname{Max}(1+\eta) P Q-C(Q)-P Q+\frac{(1+\eta) P Q r}{2} \\
\frac{\partial C}{\partial Q}=P\left(\eta+\frac{(1+\eta) r}{2}\right) \\
(1+\eta) P=\frac{2\left(\frac{\partial C}{\partial Q}-\eta P\right)}{r}
\end{gathered}
$$

$Q$ is the number of insurance contracts that insurance companies plan to sell. $C$ is the function of administration cost. $P$ is actuarial value of an insurance contract, which is independent of the quantity of insurance contracts that insurance companies plan to sell. $(1+\eta) P$ is the insurance premium that insurance companies plan to charge. $P Q$ is the total expected indemnity expenditure. $\frac{(1+\eta) P Q r}{2}$ is the interest revenue yielding from cash management. In equation (16), the relation between interest rate and insurance premium is negative. Insurance is expensive (cheap) when interest rate is low (high). In equation (15), the relation between marginal cost and interest rate is positive. Marginal cost increases because insurance companies will cut insurance premium due to high interest rate in order to sell more insurance contracts. Equation (15) and equation (16) are consistent.

The purpose of equation (14) is to demonstrate that interest rate is a common factor that affects insurance premium in addition to actuarial value for all insurance contracts. Since insurance contracts differ in kind, there is no general profit function for all insurance contracts. Readers can modify equation (14) by introducing new variables (e.g., reinsurance). In addition, readers may interest to compare insurer's profit function in this section with option writer's profit function in the next section in order to understand why option pricing is different from insurance pricing even option price and insurance premium are explained by the same independent variables.

\section{Option Pricing}

Review Hull's example in section IV in which strike price is \$21 and spot stock price is \$20. According to Black and Scholes (1973, p. 638), the price of European option call in Hull's example is negative. Option price is supposed to be compatible with partial hedge like Hull's example. It leads me to investigate the concept of option price.

We know the marginal cost to produce one extra option is zero. Thus, the supply curve of option is horizontal and demand for option has no influence on the price of option. Since supply of option determines option price and the modern theory of option pricing based on riskless portfolio and arbitrage assumption concerns demand for option only, the modern theory of option pricing shoots the wrong target. In order to explain market option price, we have to abandon the modern theory of option pricing whether the modern theory of option pricing is true or false.

Both option writers and option owners sell options in option market. The option price quoted by option writers determines market option price because option owners sell their own options following market option price. The option price quoted by option writers contains the expected loss taken over from option buyers (i.e., the actuarial value of option) as insurance premium does. In other words, expected loss is option writer's cost. Since expected loss is independent of the quantity of option, expected loss does not relate to the production cost of option.

Let $x$ be expected stock price.

$$
\begin{gathered}
c=\int_{s}^{\infty}(x-s) f(x) d x \\
p=\int_{0}^{s}(s-x) f(x) d x
\end{gathered}
$$

$c(p)$ is the actuarial value of option call (option put). $s$ is strike price. The strike price in equation (17) must be less than infinite and the strike price in equation (18) must be greater than zero. The range of strike price is $(0$, $\infty)$, which is different from the idea of Black and Scholes, who set spot stock price to be the upper limit for strike price. Thus, partial hedge is feasible. 
As insurance corporations, option writers collect option premium in the beginning of a period. Option writers pay American option buyers gradually like insurance corporations. Option writers earn $\frac{c r}{2}$ for each American option call and $\frac{p r}{2}$ for each American option put. The net actuarial value of American option call (put) is $\mathrm{c}\left(1-\frac{\mathrm{r}}{2}\right)\left(p\left(1-\frac{r}{2}\right)\right)$. Since option writers pay European option buyers at expiration date, the net actuarial value of European option call (put) is $c(1-r)(p(1-r))$.

If the option price that an option writer charges is less than the net actuarial value of option, he loses money. If the option price that a particular option writer charges is higher than the net actuarial value of option and all option writers have the same expectation about stock price, rivalry option writers can beat his quotation due to the reason that rivalry option writers can produce extra quantity of option free. Thus, the net actuarial value of option is the price of option charged by an option writer. By competition, market option price is the lowest net actuarial value of option among option writers because each option writer has his own expectation about stock price. As insurance premium, option price is expensive (cheap) if interest rate is low (high). In addition to the net actuarial value, option writers charge transaction fee in order to make profit. Transaction fee is a fixed amount of cash, which depends on the cost of per transaction, not quantity of option.

We usually use average expected stock price to study payoff instead of the probability distribution of expected stock price. I use equation (17) to show the relation between the mean value of expected stock price that is greater than or equal to strike price and the actuarial value of option call.

$$
\int_{s}^{\infty}(x-s) f(x) d x=\left(\frac{\int_{s}^{\infty} x f(x) d x}{\int_{s}^{\infty} f(x) d x}-s\right) \times \int_{s}^{\infty} f(x) d x
$$

Equation (19) means that the actuarial value of option call is equal to (the mean value of expected stock price that is greater than or equal to strike price minus strike price) multiply the cumulative probability of expected stock price that is higher than or equal to strike price. I would like to remind readers that the mean value of expected stock price that is greater than or equal to strike price depends on conditional probability. For example, the strike price is $\$ 20$ and expected stock prices with probability are $\$ 19(0.2), \$ 20(0.3), \$ 21(0.3)$ and $\$ 22(0.2)$. The mean value of expected stock price that is greater than or equal to strike price is equal to $21 \times \frac{0.3}{0.5}+22 \times \frac{0.2}{0.5}=21.4$. The expected loss is equal to $0.3 \times 1+0.2 \times 2=(21.4-20) \times 0.5$. When $\int_{s}^{\infty} f(x) d x=1$ (i.e., all potential stock prices that you expect are greater than or equal to strike price), the mean value of expected stock price that is greater than or equal to strike price is equal to average expected stock price. Thus, we can use average expected stock price minus strike price to compute the price of option call in this case. Similarly, we can derive the price of option put from strike price minus average expected stock price if $\int_{0}^{s}(s-x) f(x) d x=1$.

Option price changes under given strike price if the probability distribution of expected stock price changes. Let $g(x)$ be the new probability distribution of expected stock price. Then, $c^{*}=\int_{s}^{\infty}(x-s) g(x) d x$ and $c^{*}(1-r)-c(1-r)=(1-r) \int_{s}^{\infty}(x-s)(g(x)-f(x)) d x$. Thus, the change in option call price under given strike price does not depend on the change in spot stock price or the change in the mean value of expected stock price that is greater than or equal to strike price. Since delta hedge is based on the relation between option price and either spot stock price or expected stock price but the change in option price under given strike price depends on the change in the probability distribution of expected stock price, we cannot construct any delta hedge under this situation except that the cumulative probability that expected stock price is greater than or equal to strike price is equal to one or the cumulative probability that expected stock price is less than or equal to strike price is equal to one. It is wrong to introduce delta hedge into option pricing unconditionally like Black and Scholes (1973).

In order to study option price, I make following assumptions.

(1) There are a three months American option call maturing at 10/31/2013 and a three months European option call maturing at 10/31/2013.

(2) Strike price is $\$ 100$.

(3) The stock price of Apple is $\$ 102$ at 08/01/2013.

(4) Everybody knows that Apple will start to promote a new model of iPhone at 08/15/2013. Consequently, the Apple stock price will rise in September 2013 due to extra sales in the third quarter. I assume that the cumulative probability of expected stock price that is greater than or equal to strike price $(\$ 100)$ is equal to one and the average expected stock price will be $\$ 120$ in September 2013. In other words, the expected loss of option call with strike price equal to $\$ 100$ will be $\$ 20$ in September 2013. 
(5) The stock price of Apple will drop in October because sales declines. The average expected stock price is will be $\$ 110$ in October 2013.

Following Black and Scholes, the option price of a three months American option call is $\$ 2$. In this case, option writers will lose $\$ 18$ because option speculators will exercise American option call during September. Thus, option writers should charge $\$ 20\left(1-\frac{r}{2}\right)$ and Black and Scholes are wrong. Notice that the probability distribution of expected stock price in September is the probability distribution that brings option writers the highest expected loss and option writers should use this probability distribution to estimate expected loss because economic agents can exercise American option at any time before expiration date. It is possible that the probability distribution of the current date brings the highest loss to option writers. For example, spot stock price is greater than the average expected stock price because option writers expect that stock price will fall. I assume that the spot stock price at $09 / 15 / 2013$ is $\$ 130$. The probability corresponding to $\$ 130$ is one because $\$ 130$ is a certain price. Thus, equation (17) tells us that the loss of option writers will be $\$ 30$ if option writers sell American option call with strike price equal to $\$ 100$ at $09 / 15 / 2013$. Note that speculators will buy American option call and exercise immediately if option writers charge less than $\$ 30$ at 09/15/2013. In this example, option writers cannot earn interest revenue. Thus, the price of three months American option call at 09/15/2013 is $\$ 30$. The price function for American option call is $\operatorname{Max}\left(0, S-s,\left(S_{c}^{e}-s\right)\left(1-\frac{r}{2}\right)\right)$, which is derived from equation (17). The superscript $e$ means expectation and $S_{c}^{e}$ is average expected stock price. For American option put, we have $\operatorname{Max}\left(0, s-S\right.$, $\left.\left(s-S_{p}^{e}\right)\left(1-\frac{r}{2}\right)\right)$, where $S_{p}^{e}$ is the mean value of expected stock price that is less than or equal to strike price.

The option price of three months European option call is $\$ 10(1-r)$ because strike price is $\$ 100$ and average expected stock price is equal to $\$ 110$ at $10 / 31 / 2013$. In other words, the probability distribution of expected stock price for European option call may be different from the probability distribution of expected stock price for American option call. If you buy a three months European option call at 06/15/2013 with strike price equal to $\$ 100$, option writers will charge you $\$ 20(1-r)$ due to the reason that average expected stock price is $\$ 120$ at $09 / 15 / 2013$. Note that European option call and American option call have the same probability distribution of expected stock price in this case. Thus, the price function of European option call is $\operatorname{Max}\left(0,\left(S_{E c}^{e}-s\right)(1-r)\right)$, where subscript $E$ is expiration date. For European option put, we have $\operatorname{Max}\left(0,\left(s-S_{E p}^{e}\right)(1-r)\right)$. Since the price function of European option is different from the price function of American option, the price of European option may be different from the price of American option. Note that the price of 45 days European option call at $09 / 15 / 2013$ is $\$ 10\left(1-r^{*}\right)$ although the spot stock price at $09 / 15 / 2013$ is $\$ 130$ due to the reason that the expected loss at 10/31/2013 is $\$ 10$. Where $r^{*}$ is 45 days interest rate. Thus, option owners cannot sell their own European option call that will be expired at $10 / 31 / 2013$ by $\$ 30$ at $09 / 15 / 2013$ as Black and Scholes predicted because option buyers can get a better deal from option writers.

Option hedgers should use equation (17) and equation (18) to estimate the actuarial value of option in order to determine the demand price for option. Option hedgers' expectation may be different from option writers' expectation. If the expected loss of option hedgers is less than the expected loss of option writers (i.e., the demand price of option is less than the supply price of option), the cost of hedge is too high to practice hedge.

I use the solution for the optimal strike price of European option put listed as below to demonstrate how to compute the optimal strike price.

$$
\begin{gathered}
\sigma_{p}^{2}=\int_{0}^{s}(p-x)^{2} f(x) d x \\
\operatorname{Max} \frac{\sigma_{p}^{2}}{p(1-r)} \\
\frac{\partial \sigma_{p}^{2}}{\partial s} p(1-r)-(1-r) \sigma_{p}^{2} \frac{\partial p}{\partial s}=0 \\
\frac{\partial \sigma_{p}^{2}}{\partial s}=\frac{\partial \int_{0}^{s}(p-x)^{2} f(x) d x}{\partial s}=(p-s)^{2} f(s) \\
\frac{\partial p}{\partial s}=\frac{\partial \int_{0}^{s}(s-x) f(x) d x}{\partial s}=\frac{\partial s \int_{0}^{s} f(x) d x}{\partial s}-\frac{\partial \int_{0}^{s} x f(x) d x}{\partial s}=\left(\int_{0}^{\mathrm{s}} \mathrm{f}(\mathrm{x}) \mathrm{dx}+\operatorname{sf}(\mathrm{s})\right)-\mathrm{sf}(\mathrm{s})=\int_{0}^{\mathrm{s}} \mathrm{f}(\mathrm{x})=\pi \\
(p-s)^{2}=\frac{\sigma_{p}^{2} \pi}{p f(s)}
\end{gathered}
$$

$\sigma_{p}^{2}$ is the variance of expected loss covered by option put, which can be treated to be the reward yielding from option put hedge. Since the probability that expected stock price is equal to zero is zero, we have equation (23) 
and equation (24). Equation (23) means that the variance covered by European option put increases ( $p-$ $s)^{2} f(s)$ if the strike price of European option put increases from $s-\Delta s$ to $s . \pi$ is the cumulative probability that expected stock price is less than or equal to strike price. Equation (24) means that the actuarial value of option put increases $\pi$ dollar if the strike price of option put raises one dollar. Note that the actuarial value of option call declines $(1-\pi)$ dollar if the strike price of option call raises one dollar $\left(\frac{\partial c}{\partial s}=\frac{\partial \int_{s}^{\infty}(x-s) f(x) d x}{\partial s}=-(1-\pi)\right.$ due to $f(\infty)=0$ ). By equation $(25)$, the solution of the optimal strike price is $s=p+\left(\frac{\sigma_{p}^{2} \pi}{p f(s)}\right)^{\frac{1}{2}}$ because the strike price is supposed to be greater than the price of option put. Equation (25) shows that the optimal strike price is different from spot stock price. It implies that partial hedge is optimal. Thus, riskless portfolio is not the optimal portfolio that economic agents should construct.

Since option writers pursue profit, we have

$$
\begin{gathered}
\operatorname{Max} c(1-r) O_{c}+t T-C(T)-c O_{c}-F+c r O_{c} \\
\frac{\partial c}{\partial T}=t
\end{gathered}
$$

Equation (26) describes how option writers pursue maximum profit while option writers sell European option call. $O_{c}$ is the quantity of option call. $c(1-r) O_{c}$ is revenue generating from option call selling. $c O_{c}$ is the expenditure for expected loss. $t$ is transaction fee of option, which is a fixed amount of cash. $T$ is the number of transactions. $F$ is fixed cost to produce option. $\mathrm{crO}_{c}$ is interest revenue earning from cash management. Equation (27) requires transaction fee to be equal to the marginal cost of per transaction. Notice that fixed cost and quantity of option has no effect on option writers' decision about option price because the marginal cost of option is zero.

\section{Reviews and Conclusions}

The price of option call and the price of option put are not independent.

$$
c-p=\int_{s}^{\infty}(x-s) f(x) d x-\int_{0}^{s}(s-x) f(x) d x=\mu-s
$$

Equation (28) is different from put-call parity, $S+p=c+s e^{r t}$. Put-call parity contains two portfolios. One is riskless portfolio consisting of one share of stock and a long position of option put. The cost of this riskless portfolio is $S+p$. The other portfolio is composed of one option call plus an amount of cash equal to discounted strike price, $c+s e^{-r t}$. The strike price is equal to spot stock price (i.e., $S=s$ ) due to riskless portfolio. Since these two portfolios always have the same value, arbitrage assumption requires that these two portfolios should have the same cost. Therefore, we get put-call parity equation.

Consider two portfolios. One is riskless portfolio consisting of a short position of stock and a long position of option call. The other portfolio is composed of a long position of option put plus an amount of cash equal to $s e^{-r t}$. Economic agents are usually required to provide one hundred percent collateral for their short positions of stock by brokers. Otherwise, economic agents may sell stocks in short position, collect revenue accruing from short positions of stock selling and escape. Further, economic agents can use revenue originating from short positions of stock to buy option call if there is no cost to build up short positions of stock. In other words, speculators do not take a penny from their pocket to construct the riskless portfolio consisting of a short position of stock and a long position of option call (i.e., the net investment is zero) and return rate on capital is infinite in this case. It will make stock market in chaos because all speculators should dump stock. Thus, the value of a short position of stock is equal to spot stock price, $S$. Note that readers can review Hull's example and then acknowledge that binominal model does not handle the revenue arising from short position of option call appropriately because brokers are supposed to keep cash arising from short positions of option call selling as collateral in Hull's example.

When stock price rises, the former portfolio is break even. Thus, these two portfolios have the same value, $S$. If stock price declines to $S^{*}$, these two portfolios make the same profit, $S-S^{*}$. Consequently, these two portfolios have the same value, $2 S-S^{*}$. By arbitrage assumption, we have $S+c=p+s e^{-r t}$. This result is contradictory to put-call parity. Review section III.2 in which I argued that riskless portfolio and arbitrage assumption are inconsistent. Like binominal model, put-call parity is a false theory due to its inconsistent premises.

When an economic agent purchases stocks in stock market and then asks insurance corporations to quote price for a portfolio insurance that covers loss caused by stock price below strike price, insurers use equation (18) to estimate the actuarial value of this portfolio insurance. Similarly, insurers estimate the loss caused by stock price 
above strike price by equation (17). Thus, the actuarial value of portfolio insurance and the actuarial value of option are identical. Since both the premium of portfolio insurance and option price depend on actuarial value, equation (17) and equation (18) suggest that option price and the premium of portfolio insurance are derived from the same independent variables as I argued in section I.

We have to examine price theories of substitute products prior to this paper because price theories of substitute products must be built on the same independent variables. If we want to build an econometric model to estimate prices of substitute products by regression equations, we do not need simultaneous equation model and we do not need to consider prices interdependence. If you find that prices interdependence can improve predictability, it implies that you pick wrong independent variables.

Since arbitrage assumption is a false premise and I have proved that we can derive contradictory conclusions from a false premise, we have to overhaul financial theories based arbitrage assumption. We can extend the methodology in this paper to study the price of any derivative because all derivatives are related to hedge (i.e., risk shifting) and the marginal cost of any derivative is zero. Thus, this paper develops a general price theory for all derivatives.

This paper suggests two economic policies. Risk shifting creates a mirage that everybody is safe. But we forget the essential characteristic of risk shifting that risk cannot be wipe off when we take all economies as a whole. For example, the global economy cannot avoid loss caused by natural disasters but an individual country can. All financial crises originate from the underestimation of risk. Government should ask financial institutions, who supply derivatives, to keep enough reserve for their risk-shifting products. It is wrong that government allows financial institutions to invent new risk-shifting products in order to avoid regulations and reserve. Laissez faire regards competition and maximization of financial benefit (i.e., efficiency). Laissez faire does not relate to risk shifting because risk shifting is a trade-off between financial benefit and risk. Thus, laissez faire is not the reason to insist that government should not regulate derivatives.

Second, government should apply minimum average cost to guide social security whether government practices capitalism or socialism because partial coverage is optimal. It coincides with Ting (2012), who argued that government should keep expanding its size to provide public service until average cost reaches minimum. Once we know how much minimum average cost of partial social security is, we know how much the optimal social security tax that should be collected by government is.

\section{References}

Arrow, K. J. (1963). Uncertainty and the Economics of Medical Care. American Economic Review, 53, 941-973.

Arrow, K. J. (1965). Aspects of the Theory of Risk-Bearing. Helsinki: Yrjo Jahnsson Fundation.

Bamoul, W. (1952). The Transaction Demand for Cash: An Inventory Theoretic Approach. Quarterly Journal of Economics, 66, 545-556. http://dx.doi.org/10.2307/1882104

Black, F., \& Myron, S. (1973). The Pricing of Options and Corporate Liabilities. Journal of Political Economy, 81, 637-654. http://dx.doi.org/10.1086/260062

Borch, K. (1962). Equilibrium in a Reinsurance Market. Econometrica, 30, $424-444$. http://dx.doi.org/10.2307/1909887

Carlson, M. (2006). A brief History of the 1987 Stock market Crash with a Discussion of the Federal Reserve Response. Finance and Economics Discussion Series, Federal Reserve Board.

Cox, C. J., Stephen, A. R., \& Mark, R. (1979). Option pricing: a Simplified Approach. Journal of Financial Economics, 7, 229-264. http://dx.doi.org/10.1016/0304-405X(79)90015-1

Crack, T. F. (2009). Basic Black-Scholes: Option Pricing and Trading (2nd ed.).

Cummins, J. D. (1990). Asset Pricing Models and Insurance Ratemaking. Astin Bulletin, $125-166$. http://dx.doi.org/10.2143/AST.20.2.2005438

Davidson, W., Mark, C., \& John, T. (1992). Corporate Demand for Insurance: Some Empirical and Theoretical Results. Journal of Financial Services Research, 6, 61-71. http://dx.doi.org/10.1007/BF01046118

Geczy, C., Bernadedtte, M., \& Catherine, S. (1997). Why Firms Use Currency Derivatives. The Journal of Finance, LII, 1323-1354. http://dx.doi.org/10.1111/j.1540-6261.1997.tb01112.x

Gollier, C. (2003). To Insure or Not to Insure?: An Insurance Puzzle. The Geneva Papers on Risk and Insurance Theory, 28, 5-24. http://dx.doi.org/10.1023/A:1022112430242 
Jin, Y., \& Philippe, J. (2006). Firm Value and Hedge: Evidence from U. S. Oil and Gas Producers. The Journal of Finance, 61, 893-919. http://dx.doi.org/10.1111/j.1540-6261.2006.00858.x

Lo, A., \& Wang, J. (1995). Implementing Option Pricing Models When Asset Returns Are Predictability. The Journal of Finance, L, 87-129. http://dx.doi.org/10.1111/j.1540-6261.1995.tb05168.x

Mayers, D., \& Cliford, W. S. (1982). On the Corporate Demand for Insurance. Journal of Business, 55, $281-296$. http://dx.doi.org/10.1086/296165

Mayers, D., \& Cliford, W. S. (1983). The Interdependence of Individual Portfolio Decisions and the Demand for Insurance. Journal of Political Economy, 91, 304-311. http://dx.doi.org/10.1086/261145

Mossin, J. (1968). Aspects of Rational Insurance Purchasing. Journal of Political Economy, 76, $553-568$. http://dx.doi.org/10.1086/259427

Pratt, J. (1964). Risk Aversion in the Small and the Large. Econometrica, 32, $122-136$. http://dx.doi.org/10.2307/1913738

Raviv, A. (1979). The Design of an Optimal Insurance Policy. American Economic Review, 69, 84-96.

Singh, V. K. (2013). Empirical Performance of Option Pricing Models: Evidence from India. International Journal of Economics and Finance, 5, 141-149. http://dx.doi.org/10.5539/ijef.v5n2p141

Ting, C. C. (2010). The Optimal Size of the Firm and Growth theory. European Journal of Economics, Finance and Administrative Science, 25, 25-28.

Ting, C. C. (2011). Note on the Optimal Size of Government. European Journal of Business and Economics, 3 , 41-42.

Ting, C. C. (2011). The True Cause of Business Cycle. European Journal of Business and Economics, 4, 47-51.

Ting, C. C. (2013). A Note on Option Pricing: the End of Black-Scholes Formula. eCanadian Journal of Business and Economics, 20-25.

\section{Copyrights}

Copyright for this article is retained by the author(s), with first publication rights granted to the journal.

This is an open-access article distributed under the terms and conditions of the Creative Commons Attribution license (http://creativecommons.org/licenses/by/3.0/). 